\title{
EL ATENEO DE MADRID Y EL PROBLEMA \\ COLONIAL EN LAS VÍSPERAS DE LA GUERRA DE INDEPENDENCIA CUBANA
}

POR

\author{
LUIS MIGUEL GARCÍA MORA \\ Fundación Histórica Tavera \\ Madrid
}

\begin{abstract}
El problema colonial fue un tema debatido en profundidad en el Ateneo de Madrid en los momentos previos a la definitiva Guerra de Independencia Cubana (1895-1898). La idea que se defiende es que más que tener lugar un debate científico sobre el problema colonial contemporáneo, se trataba de aprovechar la plataforma ateneista para concienciar a la opinión pública y la élite politica española de la necesidad de una reforma colonial que por las mismas fechas se discutía en el Parlamento.
\end{abstract}

En el siglo pasado el Ateneo de Madrid era el foco de discusión de la última teoría política, de la novísima filosofía y de la postrera producción literaria. En sus secciones se discutía de todo y por todos, sin los exclusivismos que se apreciaban en los estamentos de la cultura oficial, más concretamente en la Universidad, en donde se había acabado con la libertad de cátedra

\footnotetext{
Proyecto financiado por la Comunidad de Madrid, n. ${ }^{\circ}$ 077/92. Una versión preliminar de este trabajo fue presentado al Primer Congreso Internacional de Ateneos Españoles e Iberoamericanos, celebrado en Madrid en mayo de 1993. El autor desea agradecer los comentarios que en su día hicieron a este trabajo Antonio Santamaría, Consuelo Naranjo y Elena Hernández Sandoica.
} 
$y$, consecuentemente, con la libertad de pensamiento (1). En sus salones, al decir de los contemporáneos, la pasión política se transformaba en serena indagación científica; se dejaban a un lado la demagogia y la polémica, abriéndose paso el conocimiento preciso sobre el tema abordado. Pero además de libertad y erudición, el Ateneo tenía un tercer atractivo: lo que allí se decía y por quién se decía -la más alta intelectualidad del momento- no caía en el vacío, casi siempre traspasaba las paredes del edificio de la calle del Prado y, a través de la prensa, que puntualmente recogía sus actividades, llegaba a la generalidad del país. El Ateneo era, por tanto, un importante conformador de la opinión pública, digno de tener en cuenta por la élite política de la época.

La cuestión colonial, más concretamente la realidad cubana, en los albores de su definitiva guerra de independencia, era uno de esos temas que por lo "espinoso" (permítasenos el concepto) estaba llamado a ser discutido en la «Docta Casa». Entre enero y febrero de 1895, a la vez que el gobierno liberal trataba de sacar adelante una reforma del sistema político y administrativo, que desagraviase a la mayor de las Antillas de la funesta política sobre ella practicada, y que permitiese asegurar el dominio de España sobre bases más sólidas que la represión y marginación del elemento criollo, en el Ateneo se discutía la realidad colonial por los mismos diputados cubanos que estaban llamados a participar en los debates de las Cortes. De esta manera, contribuía a crear el clima de opinión previo a la toma de decisión política, tratando en extenso y abordando todas las facetas del problema «en un lugar -recogía la prensa habanera de la época- donde no se consienten necias interrupciones en que lucen su habilidad algunos de los graciosos del Congreso, ni tampoco puede emplearse el recurso de sacar el cristo y ahogar la voz de un orador en una explosión de patriotería cursi y extemporánea» (2).

(1) Luis Miguel García Mora, "Un cubano en la corte de la Restauración: la labor intelectual de Rafael Montoro, 1875-1878». Revista de Indias, n.os 195/196, Madrid, CSIC, 1992, págs. 443-475.

(2) "El problema antillano en el Ateneo». El País, La Habana, 29-1-1895. Las cursivas son del original del periódico.

\section{R. I., 1996, n. 207}


En definitiva el Ateneo llevó a su seno el problema nacional por excelencia. Su cátedra se convirtió en la plataforma de la política antillana (3). Todos los políticos del momento eran conscientes que el dominio de España en Cuba dependía de lo acertado que fuese la inaplazable reforma del sistema colonial, propugnando cada cual sus soluciones, pero viéndose en la necesidad de llegar entre todos ellos a una fórmula de consenso que asegurase cuanto antes el futuro de las Antillas. Cómo y quiénes fueron los encargados en el Ateneo de «esclarecer sus determinaciones a la luz de una reflexión previsora y de un patriotismo grave y pensador» (4) es el objeto de este artículo. Como paso previo consideramos necesario dar unas pinceladas sobre la realidad colonial cubana del siglo XIX.

\section{Cuba y España en el Último tercio del Siglo XiX}

Cuba y Puerto Rico eran las dos únicas posesiones que España pudo salvar de su gran imperio americano. Sin embargo, a lo largo del siglo XIX se fue desarrollando un proceso de concienciación nacional que empujó a Cuba hacia la independencia sin que desde España se realizase una política lo suficientemente acertada para impedir el proceso, retrasarlo o, en último término, hacerlo lo menos violento posible. Por el contrario, la manera de gobernar la Gran Antilla no hizo más que diferenciarla de la Península, aún cuando desde ésta se proclamaba como objetivo político la asimilación entre colonia y metrópoli.

Socialmente el mantenimiento de la esclavitud hasta la tardía fecha de 1886 no hacía más que introducir un elemento de distorsión que dificultaba el equiparamiento de una sociedad española situada a ambos lados del Atlántico, más cuando la influencia'cultural africana iba, poco a poco, desdibujando el perfil exacto de la cultura criolla blanca y europea. Es necesario resaltar que el sentimiento de pertenecer a una cultura común es el factor que ejerce más fuerza en el sentimiento de

(3) Así lo estimaba, Testifonte Gallego, La insurección cubana. Madrid, Imprenta central de los ferrocarriles, 1897, pág. 247.

(4) «En el Ateneo de Madrid», Diario de la Marina. La Habana, 12-1-1895. 
unidad de una sociedad (5). Desde el punto de vista político, las Antillas se habían mantenido al margen del liberalismo que, como forma de organización política, se venía desarrollando en la Península desde 1834. Las distintas constituciones que se dieron desde esa fecha hasta 1881 no rigieron en Cuba. La isla careció del derecho de representación en Cortes y en ella subsistió una legislación especial siempre sometida a la libre voluntad del capitán general quien, amparándose desde 1825 en la Ley de Facultades Omnímodas, por la que podía gobernar la colonia como si de una plaza sitiada se tratase, mantuvo a la isla en el más completo absolutismo. Desde el punto de vista económico, la España del siglo xIx carecía de la infraestructura precisa para desarrollar un moderno colonialismo, capaz de comercializar y transformar las materias primas, principalmente el azúcar, obtenidas de Cuba, y a su vez, suministrar los necesarios implementos industriales para mantener la especialización productiva. Esto ocasionó, que los Estados Unidos se convirtiesen en la metrópoli económica de la isla, en ellos se encontraba un mercado para su azúcar, los barcos para su comercio y la maquinaria para sus ingenios azucareros. En esta situación, España trató, desde la legislación de suplir sus deficiencias estructurales, sometiendo a la isla a una elevada presión fiscal articulada sobre unos altos aranceles, que engordaban la renta de aduanas, a la vez que trataban de reservar el mercado antillano para la producción peninsular (6).

Las consecuencias de toda esta situación estallaron en la Guerra de los Diez Años (1868-1878). La independencia de la co-

(5) Sobre este aspecto puede verse Josef OPATRNÝ, "Peculiaridades del desarrollo nacional cubano" en Consuelo NARANJo y Tomás Mallo (eds.), Cuba, la Perla de las Antillas, Madrid/Aranjuez, CSIC/Editorial Doce Calles, 1994, págs. 249-259.

(6) Este modelo de "expolio colonial» ha sido perfectamente definido por Manuel Moreno Fraginals, El Ingenio, complejo económico social cubano de azúcar, 3 vols., La Habana, Editorial de Ciencias Sociales, 1978, vol. II, págs. 130-134. El papel que jugaba en la época de la Restauración el mercado colonial puede verse en Jordi MALUQuer DE MOTES, "El mercado colonial antillano en el siglo XIX", en Jordi NADAL y Gabriel TORTELla (eds.), Agricultura, comercio colonial y crecimiento económico en la España contemporánea. Barcelona, Ariel, 1974, págs. 322-356. José María SERRANO SANZ, El viraje proteccionista de la Restauración. La política comercial española, 1875-1895, Madrid, Siglo XXI, 1987, págs. 65-71 y 195-197.

R. I., 1996, n.o 207 
lonia era para los cubanos la solución a todos sus problemas, conscientes de que era el gobierno de España el causante de los mismos. Sin embargo, tras una década de intensa lucha ni éstos habían logrado su objetivo, ni los españoles consiguieron acabar mediante la fuerza con el movimiento independentista. Fue preciso un pacto (y al acceder a él España reconoció cierta legitimidad a los insurrectos) para terminar con la guerra. En febrero de 1878 se firmó la Paz del Zanjón, por la que España se comprometió, en cierta medida, a transformar el régimen colonial que había venido soportando la isla desde principios del siglo XIX.

El período subsiguiente a la firma de la paz inauguró una coyuntura propicia con respecto a la reforma colonial, pero como bien se lamentaba uno de los conferenciantes del Ateneo, «entonces [que] pudo hacerse todo sin resistencia, con grandes facilidades, con el general asentamiento", no se concedió a Cuba más que una representación en Cortes y una legislación provincial y municipal, que aunque basadas en la peninsular, poco tenían en común con ella (7). No se dio más que un nuevo orden institucional, prometiéndose que desde la participación en el mismo (y no mediante procesos revolucionarios) los cubanos podrían ver satisfechas sus aspiraciones. Pero a pesar de las buenas palabras y de las peticiones de los diputados cubanos en las Cortes, las reformas no llegaron. Es indiscutible que se había introducido cierta modificación en el modelo colonial, pero, como afirma Foner, «las principales mejoras en asuntos políticos y constitucionales que se lograron después del Zanjón fueron cosa de fraseología legal más que realización práctica» (8), mientras que los verdaderos cambios a la altura de 1895 seguían sin cumplirse.

(7) Eliseo Giberga, «El problema colonial contemporáneo. Conferencia pronunciada en el Ateneo de Madrid el 14 de enero de 1895" en Obras Completas, 4 vols., La Habana, Imprenta y papelería de Rambla y Bouza, 1930, vol. I, págs. 215-216. Sobre las dificultades de realizar una política reformista inmediatamente después de firmada la Paz de Zanjón puede verse Luis Miguel García Mora, "Tras la revolución, las reformas: el Partido Liberal cubano y los proyectos reformistas tras la paz de Zanjón» en NARANJo y MALLO [5], págs. 197-212.

(8) Philip S. Foner, Historia de Cuba y sus relaciones con los Estados Unidos, 2. vols., La Habana, Pueblo y Educación, 1988, vols. II, pág. 321. 
La situación en la isla de Cuba cada vez era más agobiante. A la falta de una participación efectiva de los criollos en los asuntos del país, se unían graves problemas socieconómicos. En Madrid, la prensa recogía en sus páginas estas inquietudes. El diario conservador, La Época, denunciaba la difícil situación de los campesinos, que mientras en otros años cobraban en el período de la zafra azucarera de 25 a 30 pesos, en 1895 no percibían más de 10 pesos. Al otro lado de la pirámide social cubana el descontento era idéntico. En el artículo anterior, el diario canovista se hacía eco de una carta enviada por el hacendado y diputado autonomista, Rafael Fernández de Castro, al Círculo de Hacendados, en la que proponía la paralización de toda actividad agrícola e industrial, a la vez que llamaba al boicot de los productos de procedencia peninsular, hasta que el gobierno no procediese a la modificación del orden económico imperante. En otras palabras, se planteaba por parte de uno de los más importantes propietarios cubanos, una huelga general (más concretamente un cierre patronal) (9), mientras que las clases menos favorecidas veían en el bandolerismo, cada vez más vinculado al independentismo, la única salida a su angustiosa situación (10).

El gobierno, que desde diciembre de 1892 estaba en poder de los liberales de Sagasta, había intentado poner remedio a este orden de cosas con poca fortuna debido, principalmente, a la dura oposición que los conservadores, tanto cubanos como peninsulares, habían hecho al proyecto de reformas del régimen político y administrativo de Cuba y Puerto Rico, presentado a las Cortes por el ministro de Ultramar, Antonio Maura, en

(9) "Noticias de última hora», La Época, Madrid, 7-1-1895. La carta de Fernández de Castro puede consultarse en El Imparcial, Madrid, 8-1-1895. Este periódico se lamentaba en su editorial del mismo número, "El peor de los sistemas", de que era la actitud del gobierno con respecto a la cuestión cubana la que provocaba respuestas como la de Rafael Fernandez de Castro.

(10) Sobre la relación independentismo con bandolerismo, véase Louis A. Jr. PÉREZ, "Vagrants, Beggars, and Bandits: Social Origins of Cuban Separatism, 1878-1895", American Historical Review, vol. 90, n. ${ }^{\circ}$ 5; 1985, págs. 1092-1121, especialmente 1118-1121. Una aportación más reciente en Manuel de Paz SÁnChez, José Fernández Fernández y Nelson López NoveGIL, El bandolerismo en Cuba, 1800-1933. Santa Cruz de Tenerife, Taller de Historia, 1993.

R. I., 1996, n. ${ }^{\circ} 207$ 
junio de 1893 (11). El joven ministro, consciente de la necesidad del cambio en la gestión de los asuntos ultramarinos, dotó a estas posesiones de un mayor grado de autonomía política y descentralización administrativa que pusiese remedio a los abusos y corruptelas que se venían observando en la aplicación de las leyes (12). La necesidad de Maura se hacía anhelo, mas aún cuando un año antes se había constituido el Partido Revolucionario Cubano. A partir de aquel momento, el separatismo adquirió unos contornos más precisos, al conseguir José Martí convertir un movimiento independentista, difuso y disperso, en un potente partido revolucionario; si España quería seguir manteniendo su soberanía en Cuba debía cambiar sustancialmente su política.

El tiempo fue pasando, el proyecto de reformas no avanzaba y Maura se vio obligado a abandonar el gobierno ante la imposibilidad de llevar a cabo sus planes. Por otra parte, las circunstancias en que se encontraba Cuba se agravaron notablemente. En 1890, la nueva legislación aduanera norteamericana, conocida como Bill McKinley, ponía nuevas trabas al acceso de los productos cubanos a su principal mercado. Ante esta situación, y teniendo en cuenta que los Estados Unidos absorbían más del $80 \%$ de sus exportaciones, las principales cooperaciones económicas de Cuba presionaron al gobierno de la metrópoli con el fin de conseguir un tratado de reciprocidad comercial que restableciera las relaciones comerciales. Fruto de esta presión fue la firma del Tratado Foster-Cánovas

(11) Sobre las Reformas Maura, el trabajo más completo hasta el momento, si bien obvia toda la documentación depositada en el Archivo de la Fundación Maura, es el de James Durnerin, Maura et Cuba. Politique coloniale d'un ministre libéral, París, Annales Litteraries de l'Université de Besançon, Les Belles Lettres, 1978. También es de interés la consulta de Antoni MARIMON I RIUTORT, La politica colonial d'Antoni, Maura: les colònies espanyoles de Cuba, Puerto Rico i les Filipines del segle XIX. Palma de Mallorca, Documenta Balear, 1994 y Javier TUSELL, «Maura una propuesta para la solución del problema de Cuba» en La presencia militar española en Cuba (1868-1895). II Jornadas de historia militar, Madrid, Ministerio de Defensa, 1995, págs. 111-124.

(12) Melchor FERNÁNDEZ AlmAgro, Historia política de la España contemporánea, 2 vols., Madrid, Ediciones Pegaso, 1959, vol II, pág. 191. 
en agosto de 1891, que permitió un importante incremento de las exportaciones cubanas (13).

No obstante, las expectativas que abrió el tratado fueron efímeras. Tres años más tarde, en agosto de 1894, los Estados Unidos decidieron modificar nuevamente su política arancelaria, dejando sin efecto el tratado y poniendo de manifiesto las contradicciones de una economía que dependía de los Estados Unidos, pero que políticamente seguía unida a España. La nueva situación colocaba a la metrópoli, que no había sido capaz de articular las reformas político-administrativas, al borde del abismo. Era general el convencimiento de que algo había que hacer (14); en noviembre de 1894 se formó un nuevo gabinete, en el que vuelve a estar presente Maura como ministro de Gracia y Justicia, siendo el republicano de la tendencia posibilista Buenventura Abárzuza el encargado, desde la cartera de Ultramar, de lograr una fórmula que agradase a todos y le permitiese reformar el gobierno de Cuba. En esta coyuntura se desarrollaron las conferencias del Ateneo objeto de nuestro estudio.

\section{El problema colonial en el Ateneo}

En su libro sobre el Ateneo de Madrid entre 1885-1912, señala Francisco Villacorta que en esa institución «se reflejan de

(13) Lo que fue y supuso el llamado Movimiento Económico ha sido estudiado por Paul ESTRADE, "Cuba a la veille de l'independence: Le Mouvement Economique (1890-1893). I.- Faits et jalons pour son histoire», Mélanges de la Casa de Velázquez, t. XIII, París, 1977, págs. 385-424 y «Cuba a la veille de l'independence: Le Mouvement Economique (1890-1893). II-Bilan et essai d'interpretation", Melanges de la Casa de Velázquez, t. XIV, París, 1978, págs. 353-380. Sobre la influencia del tratado Foster-Cánovas en el comercio cubano véase Oscar Zanetti, "En busca de la reciprocidad", Santiago, n.o 57, Santiago de Cuba, Universidad de Oriente, 1985, págs. 165-205.

(14) Véase FERNÁNDEZ Almagro, [12], pág. 201. El Economista, periódico de Madrid, consideraba que Cuba pasaba por una «situación grave y difícil, cuya importancia crece y se agiganta por momentos, cual si con el mismo curso del tiempo hubieran de irse sumando, inflexiblemente y en inexorable forma aritmética, los errores de nuestra política, los descuidos de nuestra administración y las torpezas de nuestra conducta». Véase "El problema antillano». El Economista, Madrid, 12-1-1895. 
forma inmediata los sucesos y las inquietudes de la vida nacional e internacional. No pasa un día sin que el político, el catedrático o el periodista se acojan a su hospitalidad para dejar constancia de sus preocupaciones coyunturales, que son, en definitiva, el reflejo de las tensiones sociales y de los problemas más vitales de la España de la época» (15). No es de extrañar, por tanto, que en enero de 1895 discutiese sobre el problema cubano, en las postrimerías de su definitiva crisis. Con esta actitud, el Ateneo de fines de siglo volvió a estar a la altura de las circunstancias, y llevó a la opinión pública lo que ésta demandaba. Tanto en el anuncio de sus conferencias, que publicó toda la prensa de la capital, como en el prólogo del libro a que dio lugar el asunto debatido, se puede observar esta intención. En el mencionado prólogo, se afirma textualmente que «al dar a la estampa estos trabajos, no nos mueve otra idea que una amplia y generosa propaganda. Queremos que se conozcan y para ello se estudien, los asuntos coloniales con toda la extensión y seriedad que merecen, pues estamos en la finísima convicción de que la general ignorancia que se tiene de estas cuestiones, es el más perjudicial y sensible obstáculo que encuentran nuestras colonias en el progresivo desenvolvimiento de su vida política-administrativa» (16).

Con anterioridad, y también en difíciles circunstancias -se estaba desarrollando en Cuba la Guerra de los Diez Años-, había tratado la "Docta Casa» el problema cubano, al hilo de un curso que sobre política colonial impartió el insigne publicista, político y ateneísta, Rafael María de Labra. Es interesante seña-

(15) Francisco Villacorta Baños, El Ateneo Científico, literario y artístico de Madrid (1885-1912), Madrid, CSIC, 1985, pág. 36.

(16) «Dos palabras» en El problema colonial contemporáneo, Madrid, [1895]. El prốlogo lo firman Gabriel Ricardo España, Luis de Hoyos Sainz y José Abril Ochoa. El anuncio de las conferencias que publicó la prensa de Madrid decía: «La importancia que en los momentos actuales revisten las reformas de Cuba han aconsejado a la junta directiva del Ateneo la organización de conferencias destinadas a dar a conocer en todos sus detalles lo que ha dado en llamarse, y no sin razón, el problema antillano. Estas conferencias serán explicadas por los diputados de Cuba, que han aceptado con toda deferencia la invitación que al efecto les ha hecho el señor Moret». La convocatoria puede verse, entre otros, en los siguientes periódicos: "Ateneo de Madrid», El Imparcial, Madrid, 1-1-1895; "Las reformas antillanas en el Ateneo», La Justicia, 1-1-1895; "Ateneo de Madrid», El Liberal, Madrid, 31-12-1894. 
lar que muchas de las preocupaciones presentes en el curso de 1869-1870 serán las mismas veinticinco años después y otra vez, en el Ateneo tendrían que volverse a denunciar. Esto nos habla de la inacción, falta de interés o capacidad de los gobiernos de la Restauración respecto de la situación de la Gran Antilla. Ya en el curso de 1869-1870 se lamentaba Labra del desconocimiento de los problemas coloniales por parte de los políticos de la metrópoli, reclamando la necesidad de aplicar los mismos criterios liberales que se aplicaban en la Península, y quejándose de una relación comercial que era un auténtico expolio económico, protegido y potenciado por unos funcionarios civiles o militares que iban a Ultramar a medrar en la escala administrativa y militar, sin tener la suficiente preparación para poder desempeñar su labor. Asimismo, ofrecía las soluciones que a la altura de 1895 todavía dudaba el gobierno en adoptar; ponía Labra el ejemplo del colonialismo británico, que bajo las bases de libertad política, autogobierno y librecambio había conseguido edificar el más próspero imperio colonial. En definitiva, pedía dar garantías al colono "para que como individuo y como ciudadano maneje sus propios negocios y asuma toda la responsabilidad de su gestión" (en otras palabras, autonomía colonial), convencido de que "hay algo superior a un pueblo que sabe gobernarse, y es un pueblo que sabe gobernar a otro pueblo» (17). Las críticas de Labra, presentes en todos sus trabajos de política colonial publicados en los últimos treinta años del siglo xIX, fueron la más tremenda acusación al liberalismo decimonónico (18); de los conservadores denunciaba su antirreformismo explícito, a la vez que se quejaba de la incapacidad de los gobiernos liberales para reaccionar con la diligencia que la importancia del asunto colonial requería.

Por otro lado, es preciso señalar que el curso de 1870 , lo mismo que el ciclo de conferencias de 1895, tuvo la clara fina-

(17) Véase Rafael María de LABRA, La colonización en là historia. Conferencias del Ateneo Científico, Literario y Artístico de Madrid, 2 vols. Madrid, San Martín, 1876, vol. I, págs. 87 y 90 .

(18) Alberto GIL NovalES «Abolicionismo y librecambio (Labra y la política colonial en la segunda mitad del siglo XIX)", Revista de Occidente, n.o 59 , año IV, Madrid, Fundación Ortega y Gasset, 1968, págs. 154-181. En especial pág. 168.

\section{R. I., 1996, n. 207}


lidad de crear un clima de opinión propicio para cuando la discusión pasase al Parlamento. De esta manera, mucho de lo que Labra dijo en su primer discurso en el Congreso de los Diputados en el verano de 1871, ya lo había adelantado un año antes en el Ateneo (19). Sin embargo, en el Ateneo de estos años, presidido por Cánovas y pobladas sus secciones por antiguos políticos conservadores desplazados del poder por la Revolución de 1868, no estaba, como ocurrió años después, por hacer propaganda de unas ideas con las que no comulgaba. Esto explica el silencio, según refiere el Conde de Romanones, que sobre aquellas conferencias, que habían obtenido un notable éxito, guardó la memoria reglamentaria de los trabajos de la institución en 1870 (20).

Hasta 1895 no se volvió a preocupar de modo exclusivo el Ateneo de la situación en Cuba. Los problemas coloniales, sus distintas tendencias e historia, fueron tratados por algunos de los más insignes ateneístas -Azacárate, Macanaz, Costa, Fabié (21)-, pero para tratar en particular la cuestión de Cuba, su condición social, política y económica, tenemos que esperar a las conferencias de enero y febrero de 1895.

Hemos dicho que la razón del ciclo de conferencias era divulgar el problema cubano, pero lo que nos interesa ahora desentrañar es hasta qué punto esta iniciativa respondió únicamente a la libre voluntad de la dirección del Ateneo o estaba condicionada por otros motivos e intereses; en otras palabras, quiénes fueron los que dictaron las conferencias y por qué. A la hora de justificar este aspecto, Segismundo Moret, en la conferencia de clausura, y al hacer la reseña de las demás, señalaba

(19) Es interesante resaltar que esta similitud entre los planteamientos de Labra en úno y otro foros ha llevado a algunos equívocos. Así, Roberto MESA afirma en su libro El Colonialismo en la crisis del siglo XIX español, 2. ${ }^{\mathrm{a}}$ ed., Madrid, ICI, 1990, confunde este curso de Labra en el Ateneo, con el discurso que tiempo después, 10-7-1871, pronunció en el Congreso de los Diputados y que constituyó el comienzo de la larga carrera parlamentaria del insigne político y propagandista.

(20) Álvaro de Figueroa y Torres, Don Rafael María de Labra y la política de España en América y Portugal. Madrid, Gráficas Ambos Mundos, 1922, pág. 8 .

(21) Para una mayor información sobre las actividades realizadas en el Ateneo durante estos años, véase Rafael María de LABRA, El Ateneo, 1835-1905. Notas históricas, Madrid, Alfredo Alonso, 1906, págs. 65-68 y 70-84. 
que no se había querido invitar a personajes peninsulares a que explicasen su concepción de la política colonial, sino que fueran los mismos cubanos los que expusieran las soluciones que de allá se traían. Al Ateneo le interesaba «el modo de ser y de sentir de aquella sociedad, (...) representando las vibraciones y las necesidades de las Antillas, ávidas de que se conozcan sus aspiraciones en los momentos solemnes en que se decidían sus destinos» (22). Pero, ¿cuál de las tres aspiraciones sobre las que se articulaba el sistema de partidos de Cuba quería el Ateneo que se difundiera y se conociese: la conservadora, la reformista o la autonomista? Sin duda alguna, la autonomista, principalmente, y, en menor medida, la reformista. Los planteamientos conservadores, bastantes reticentes a aceptar una reforma del régimen colonial sobre la que ya se estaban poniendo de acuerdo las dos principales fuerzas políticas de la metrópoli, fueron prácticamente ignorados y se eligió para explicar su programa a Tiburcio Pérez Castañeda; quien representaba la opción más avanzada dentro de éstos (23).

El peso de las conferencias recayó sobre el Partido Autonomista. De los siete conferenciantes, cinco pertenecían al mencionado partido. Es más, Rafael María de Labra, no se puede considerar que cumpliese con la condición que el propio Moret ponía para participar en las conferencias: ser cubano y venir de Cuba con las soluciones que allí se demandaban. A su vez, también fue invitado el representante autonomista en el Senado, Bernardo Portuondo, quien, aunque finalmente no participó, tampoco cumplía con los requisitos exigidos (24). El interés,

(22) Segismundo MoReT, «Resumen de las Conferencias» en El problema... [16], págs. 365-407, cita en pág. 367.

(23) Es interesante que cuando en 1891 los autonomistas se decidieron por el retraimiento electoral, Moret escribió a Montoro, su líder, pidiéndole que le recomendase, entre los diputados cubanos que viniesen a la península, un hombre de confianza con el que poder tratar de los asuntos de la isla. El elegido fue Tiburcio Pérez de Castañeda. Véase, Biblioteca Nacional «José Martí», Colección de Manuscritos de Montoro. Epistolario Pasivo: "Carta de Segismundo Moret a Rafael Montoro", Madrid, 18-2-1891, t. XIV, carta n.o 56. La designación de Pérez Castañeda se confirma en Idem, Epistolario Pasivo: "Carta de Segismundo Moret a Rafael Montoro", Madrid, 28-4-1891, t. XIV, carta n. 68 .

(24) El primitivo programa de las conferencias, en el que aparecía la de Portuondo anunciada para el 7-2-1895, puede consultarse en edición de la Tarde del Diario de la Marina, La Habana, 17-1-1895.

R. I., 1996, n. 207 
más que por conocer las aspiraciones de los distintos partidos cubanos, residía en propagar la idea autonómica, hacia la que habría de dirigirse, tarde o temprano, el gobierno de la isla. No es de extrañar, por tanto, que añus mas tarde, en noviembre de 1897, fuese el propio Moret, desde el ministerio de Ultramar, quien llevase la autonomía a Cuba.

La preponderancia del pensamiento autonomista en los debates del Ateneo se debió a la conjunción de intereses de Moret, presidente del Ateneo, y Labra, líder de la minoría parlamentaria autonomista, además de influyente ateneísta (25). Moret, prominente político liberal, había estado comprometido desde antiguo con la reforma del sistema colonial. A su iniciativa se debía la ley preparatoria de la abolición de la esclavitud de 1870. Por otra parte, los principios librecambistas de los que era abanderado le hacían simpático a los ojos de los autonomistas, para quienes la desaparición de las trabas arancelarias eran condición indispensable para que aumentase la exportación de azúcar. Finalmente, Moret había tratado de cubrir la ausencia autonomista de las Cortes entre 1891-1893, manteniéndose en contacto con la dirección del partido en La Habana y articulando con Labra -que en esta etapa actuó como su representante oficioso- la actuación parlamentaria respecto de los temas antillanos (26).

(25) Sobre la labor realizada por Rafael María de Labra en el Ateneo de Madrid, véase Ulpiano VICENTE HeRnÁNDEZ, Don Rafael María de Labra y Cadrana. Reformador de la educación nacional. Granada, Universidad de Granada, 1992, pág. 71 y sigs. Otras aproximaciones recientes a la figura de Labra pueden encontrarse en Elena HERNÁNDEZ SANDOICA, "Rafael María de Labra y Cadrana (1841-1919): una biografía política», Revista de Indias, Madrid, CSIC, 1994, n.o 200, págs. 107-136; Luis Miguel GARCía MORA, «Rafael María de Labra y la utopía colonial (esbozo biográfico)», Tzintzun, n. ${ }^{\circ} 21$, Morelia, Instituto de Investigaciones Históricas de Universidad Michoacana de San Nicolás Hidalgo, 1995 (en prensa); Antonio SERRANO DE HARO, "Tres notas sobre Rafael María de Labra" en Consuelo NARANJo, Miguel Ángel PUIG-SAMPER y Luis Miguel García Mora (eds.), La Nación Soñada: Cuba, Puerto Rico y Filipinas antes del 98, Aranjuez, Doce Calles, 1996 (en prensa).

(26) Para comprobar este supuesto ver las cartas que entre febrero de 1891 y diciembre de 1892 dirigió Moret a Montoro en Biblioteca Nacional "José Martí», Colección de Manuscritos de Montoro. Epistolario pasivo, t. XIV, cartas números $56,62,68,70,74,81$ y 85 . Ya en 1883, el órgano de expresión en la prensa metropolitana de los autonomistas cubanos alababa la posición de Moret con respecto de los asuntos ultramarinos, asegurando que defendía 
Por su parte, el autonomismo, dirigido en la Península por Labra, era consciente de la necesidad de hacer una propaganda activa de su ideario, bastante desconocido y mal interpretado por los sectores políticos de la metrópoli, justo en el momento en que se estaba discutiendo la reforma colonial. En su campaña se debía aprovechar toda oportunidad, más allá de la labor parlamentaria, para dar a conocer sus aspiraciones. La presencia de oradores autonomistas en las distintas instituciones científicas y culturales, y preferiblemente en el Ateneo al ser de mayor importancia, fue el mecanismo adecuado para conseguir el fin perseguido. De esta manera, en la reunión de los parlamentarios autonomistas de 5 de diciembre de 1894 se acordó que se diesen "Conferencias públicas en el Ateneo y otros centros, con el fin de ilustrar a la opinión peninsular acerca de los antecedentes, condiciones y caracteres del problema antillano" (27). Días más tarde, en otra reunión celebrada el 20 de diciembre de 1894 se afirmaba, según El Liberal, que en la misma se "ocuparon de las conferencias de propaganda que van a dar en el Ateneo, y hablaron después con el señor Moret, entregándole una nota con los puntos que prefieren tratar cada uno" (28). En definitiva, el autonomismo cubano trató de remediar uno de los males que había sufrido: el desdén de la opinión pública peninsular y de algunas personalidades políticas que podían haber contribuido a divulgar el concepto de autonomía, definiendo su verdadero sentido (29).

principios cercanos a los del autonomismo. Véase "La cuestión antillana y el Sr. Moret", La Tribuna, Madrid, 20-1-1883. Sobre el papel jugado por Moret y el partido liberal en la Restauración puede consultarse el trabajo de Antonio ELORZA, "Los temas políticos de la Restauración a través de un pensador liberal»; Cuadernos Hispanoamericanos, Madrid, Instituto de Cultura Hispánica, 1966, n. ${ }^{\circ} 197$, págs. 278-316.

(27) "Minoría autonomista». El liberal, Madrid, 6-12-1894.

(28) "Los autonomistas", El liberal, Madrid, 21-12-1894.

(29) Sobre esta crítica al Partido Autonomista, véase el artículo «Los errores del Partido Liberal Autonomista», Revista Contemporánea, Madrid, 15-4-1895, págs. 33-43, especialmente la página 40. Hay que señalar que la campaña de los autonomistas aspiraba también a que se conocieran las opiniones de los políticos españoles con relación a la reforma colonial. Así lo manifestó Eliseo Giberga en la reunión de la minoría autonomista del 12 de 12 de 1894, recogiendo su sugerencia el periódico El Liberal, dirigido por otro diputado autonomista, Miguel Moya. Véase Biblioteca Nacional «José Martí»,

\section{R. I., 1996, n.o 207}


El Ateneo era la tribuna adecuada para hacerse oír. Por su parte, Moret conseguía allanar el camino de la reforma al partido del gobierno al cual pertenecía, si bien mostró su preferencia por un planteamiento más avanzado que el defendido por los ministros Abárzuza y Maura, y que curiosamente coincidió con el que su hijo, también diputado, mantuvo en la comisión parlamentaria encargada de estudiar la transformación del sistema colonial antillano (30).

No es casual que los sectores conservadores se mostrasen contrarios a la iniciativa del Ateneo. Moret recogió estas críticas en su discurso, mientras que Labra, en el suyo, negó el carácter partidista de las conferencias y justificó el abandono del Parlamento para discutir sobre los problemas cubanos, por la libertad con que se podían tratar en el Ateneo (31). A pesar de ello, La Época no dudó en condenar la preponderancia del elemento autonomista y el órgano de los conservadores cubanos, Unión Constitucional, fue más allá, al atribuir a los diputados autonomistas la iniciativa del Ateneo, acusándoles de instrumentalizar a la institución en beneficio propio (32).

Las conferencias se articularon en tres bloques. El primero lo desarrollaron Labra y Giberga. Labra se centró en analizar el carácter de la colonización española en América, poniendo de manifiesto el sentido eminentemente político de la misma y la necesidad de la reforma como mejor antídoto frente al separatismo. Valoró el progreso colonial observado desde la Paz del Zanjón, pero señalando que la culminación lógica de ese proceso era la reorganización del gobierno interior de las Antillas y

Colección de Manuscritos de Montoro. Actas de la Minoría Parlamentaria Autonomista, t. XLII, sesión del 12-12-1894. La información abierta por El Liberal se puede consultar en los números publicados entre el 30-12-1894 y el 9-1-1895, con el título de "La fórmula de Cuba».

(30) Véase "La política del día. Cuestiones antillanas», El Imparcial, Madrid, 11-12-1895.

(31) Segismundo MoRET [22] y Rafael María de LABRA, "Carácter de la dominación española en América» en El problema... [16], págs. 1-99, especialmente pág. 5 y sigs.

(32) "En el Ateneo. Conferencia del Sr. Pérez Castañeda», La Época, Madrid, 18-1-1895 y «En el Ateneo. Conferencia del Sr. Moret sobre el problema antillano", La Época, 22-2-1895. Los artículos de la Unión Constitucional son «Labra y el Diario», 16-1-1895 y «Recortes», 30-1-1895. 
la modificación de su régimen económico. Giberga habló sobre los caracteres generales de ia sociedad colonial cubana, para posteriormente revisar la política practicada en Cuba desde las Cortes de Cádiz, concluyendo que la reforma prometida por el gobierno en 1893 levantó unas esperanzas en Cuba, que no debían ser defraudadas si España quería conservarla (33).

Este primer bloque de conferencias tenía como finalidad servir de introducción a la política colonial de España en Cuba, sin tener que entrar en consideraciones sobre la actualidad política, pero los dos diputados autonomistas condujeron las reflexiones históricas hacia la necesidad de aprobar la modificación del sistema colonial. De esta manera, cuando en el Ateneo se aplaudió el discurso de Labra, aparte de reconocer el conocimiento que sobre los asuntos coloniales tenía el orador, era "un aplauso unánime, que se trocaba en censura contra los que pretend[ían] mantener ese estado de cosas" (34) en clara referencia a los que se oponían a la transformación del modelo colonial.

La intervención de Labra sirvió para contestar a aquellos políticos republicanos (especialmente Azcárate y Salmerón) que venían defendiendo que el fin último de toda colonia era la emancipación. Juicios como ése diticultaban el buen entendimiento, por parte de los políticos metropolitanos, de lo que significaba la autonomía y hasta dónde se quería llegar con ella. Por ello, la minoría parlamentaria autonomista aprobó en su sesión de 5 de diciembre de 1894 -la misma reunión en la que se determinó la necesidad de realizar una campaña de propaganda desde distintas instituciones científicas y, en especial, desde el Ateneo- que, frente a las opiniones de Azcárate y Salmerón, se opusiese la teoría de que con la autonomía se podía llegar a un modelo de federación imperial, al estilo británico, sin ser necesaria, por tanto, la emancipación de las colonias. En la reunión se determinó que fuera Labra el encargado de establecer el lugar y el momento oportuno para defender este principio. Y, como no, éste eligió la "Docta Casa» para encubrir bajo un ropaje aparentemente teórico, una

(33) El trabajo de LABRA "Caracter...», [31]; para el de Eliseo GiBERGA en Obras...,[7], vol. I, págs. 180-226.

(34) "El problema antillano en el Ateneo», El Liberal, Madrid, 11-1-1895.

R. I., 1996, n. 207 
necesidad de la política del momento. Además, la estrategia autonomista funcionó perfectamente, ya que el mismo Moret se mostró partidario de esa fórmula del derecho colonial que era la federación imperial (35).

El siguiente bloque de conferencias trató de mostrar las distintas soluciones que sobre la organización política de la colonia ofrecían los tres principales partidos cubanos. En este momento sí intervinieron diputados de otras tendencias para explicar el programa de sus respectivas agrupaciones. Así, Tiburcio Pérez Castañeda, en nombre de los conservadores cubanos, estimaba que la política de la metrópoli debía seguir por el camino de la asimilación de su colonia, llevando a Cuba las mismas leyes que rigiesen en la Península, hasta que quedase convertida en una provincia más, con iguales derechos y deberes. Sin embargo, el orador conservador, aparte de exponer su programa aprovechó la ocasión para hacer un duro ataque a las reformas Maura y a la fórmula de transacción de la misma que pretendía llevar a cabo el ministro Abárzuza. Finalmente, olvidando el carácter teórico que debía haber tenido su conferencia, propuso a las demás fuerzas políticas cubanas un pacto sobre la rebaja del censo electoral, aspecto que los autonomistas no dudaron en aceptar (36). Aprovechando su intervención en el Ateneo, el diputado conservador intentó ofrecer fórmulas alternativas de reforma a las de gobierno, con las que no estaba del todo de acuerdo.

(35) Para los acuerdos de la reunión autonomista, véase el acta de la reunión de la minoría parlamentaria autonomista del 5-12-1894 en Colección..., [29]. Sobre el apoyo de Moret a la fórmula esbozada por Labra, "Ateneo de Madrid", El Imparcial, Madrid, 22-2-1895. La opinión de Salmerón de que las colonias pueden emanciparse queda recogida en su órgano de prensa. Véase «Componendas». La Justicia, Madrid, 15-2-1895.

(36) Véase Tiburcio PÉREZ CASTAÑEDA, "El programa asimilista», en El problema..., [16], págs. 161-201. Para la actitud de los autonomistas ante el ofrecimiento de Castañeda, ver «El problema antillano en el Ateneo. Conferencia del Sr. Castañeda», El Liberal, Madrid, 18-1-1895. 
Las siguientes conferencias, la del diputado del Partido Reformista, Eduardo Dolz, y la del autonomista, Rafael Montoro, también fueron más allá de la defensa teórica de su programa, para referirse a la fórmula reformista que estaba estudiando el Ministerio de Ultramar. Dolz mostró el total apoyo de su partido a las reformas, ya que éste había nacido dos años antes con el único objetivo de que éstas se llevasen a cabo. Montoro consideraba que sin ser la reforma propuesta por Maura y retomada por Abárzuza el objetivo de su partido, la apoyaban por considerarla un avance en materia de organización colonial (37).

En el último bloque de conferencias se analizó las relaciones mercantiles entre la metrópoli y las Antillas, y la situación administrativa y financiera de Cuba. Eran dos temas que, al no tener un carácter exclusivamente político, podían haber sido abordados por cualquiera de los representantes cubanos en las Cortes. Sin embargo, fueron otra vez los autonomistas, Emilio Terry y José Antonio del Cueto, los encargados de poner de manifiesto cómo las nefastas consecuencias que el régimen económico y administrativo podían ser evitadas con la aplicación de la autonomía colonial (38).

En definitiva se puede observar cómo los distintos oradores abandonaron el pretendido cientificismo a la hora de exponer sus doctrinas políticas, zambulléndose en la más palpitante actualidad política. No podía ser de otro modo: les interesaba más la propaganda, en los momentos que por todos ellos se estaba negociando el futuro de Cuba, que la explicación teórica de sus soluciones. El debate científico sobre el problema colo-

(37) Véase Eduardo Dolz, «El programa reformista», en El problema..., [16], págs. 203-273 y Rafael MonTORO, «El programa autonomista», en El problema..., [16], págs. 275-308.

(38) Véase Emilio TERRY, «Relaciones comerciales de Cuba y Puerto Rico con la metrópoli» en El problema..., [16], págs. 309-335 y José Antonio del CUETO, "Situación administrativa y financiera de las islas de Cuba y Puerto Rico», en El problema..., [16], págs. 337-363. Para la oposición conservadora a las opiniones autonomistas propuestas por Terry puede consultarse «En el Ateneo. Conferencia del Sr. Terry». La Época, Madrid, 27-1-1895. Sin embargo, para los republicanos dicha conferencia había demostrado, sin lugar a dudas, la necesidad de llevar el régimen autonómico a Cuba. Véase «En el Ateneo. Conferencia del Sr. Terry", La Justicia, Madrid, 27-1-1895.

\section{R. I., 1996, n. 207}


nial se desarrolló también por estas fechas en el Ateneo, pero en la Sección de Ciencias Históricas, sin tener tanta influencia en la opinión pública (39). Los conferenciantes no hablaban para teóricos del colonialismo, sino para un auditorio compuesto en su mayor parte por políticos, estando presentes todos los diputados cubanos y muchos de los peninsulares (40).

A los oradores del Ateneo, lo que verdaderamente les interesaba, era crear un clima de opinión favorable a las reformas para cuando éstas pasaran a discutirse a las Cortes. Todo cuanto se dijo tuvo una amplia repercusión en la prensa peninsular y cubana. Día a día, los periódicos dieron noticias sobre los arreglos entre los distintos partidos para lograr una fórmula de entendimiento que resolviese la cuestión cubana y, a la vez, publicaban extensas reseñas de cuanto se estaba discutiendo en el Ateneo. Así, el 30 de enero Cueto pronunció la última conferencia, a falta del resumen de Moret, y la fórmula de Abárzuza se comenzaba a discutir el 7 de febrero, para aprobarse el 18 del mismo mes. Tres días más tarde, Moret cerró las confencias, entonando, según reseñó la prensa de la época, un auténtico himno de alabanza de lo que recientemente acababa de aprobar el Parlamento español (41).

Las conferencias del Ateneo habían significado muchas cosas. Habían ayudado a acabar con el antiguo régimen colonial, adelantando la nueva posición del gobierno de Madrid hacia los partidos de Cuba. La política recién inaugurada ya no necesitaba del intransigente españolismo de los conservadores cubanos y tenía que abrirse hacia autonomistas y reformistas si quería cimentar las bases de una nueva relación colonial. En la conferencia de cierre dada por Moret se observó claramente este nuevo espíritu, pues a la vez que elogiaba las reformas recién aprobadas, criticaba la conferencia de Pérez Castañeda y excluía a los conservadores como fuerza política

(39) «En el Ateneo», La Justicia, 17-1-1895, se hace eco de la conferencia pronunciada por el secretario de la Sección de Ciencias Históricas sobre la política colonial de España.

(40) Véase "El problema antillano en el Ateneo», El Liberal, Madrid, 15-1-1895.

(41) Véase "El problema colonial en el Ateneo», El País, La Habana, 14-3-1895 que recogió la opinión citada del órgano silvelista, El Tiempo, Madrid, 22-2-1895. 
en el futuro de Cuba, que para Moret habían muerto con el antiguo régimen colonial (42). En su lugar colocaba al nuevo partido Reformista, también de talante conservador, que recogía los frutos del apoyo al plan de reformas que el gobierno había intentado desde 1893.

Por su parte, los autonomistas habían conseguido llevar a la opinión pública metropolitana una imagen moderada y conciliadora, que rompía con la de seudoseparatista que hasta ese momento se tenía de ellos. Para el diario conservador, La Épo$c a$, los autonomistas consiguieron este fin a costa de no poner en claro sus verdaderas ideas (43). No obstante, esa opinión no era compartida por otros medios más cercanos a las posiciones del Partido Autonomista, para quienes las conferencias del Ateneo habían «desvanecido muchos recelos patrióticos, especialmente en esa gran masa social, que sin formar en línea dentro de ningún partido, influye más de lo que se cree en los asuntos públicos» (44). Para el español medio, según El Nuevo Mundo, a partir de lo visto en la calle del Prado, los autonomistas eran cubanos, pero no antiespañoles; cultos y modernos, gente que piensa y por ello, más opuestos a una independencia que sumiría en la ruina a la isla, que a la autoridad de un gobernador general puesto por España. En definitiva, los autonomistas habían transmitido una imagen de moderación (45).

En conclusión, el Ateneo había sabido explicar la situación de Cuba, lo que justificaba la política reformista que el gobierno se apresuraba a aprobar por aquellas fechas y para la que necesitaba todo el apoyo que pudiera conseguir. Por eso Moret afirmaba que el Ateneo había cumplido su misión y que cuando alguien le decía que las reformas eran un sálto en las tinieblas, él consideraba que en el Congreso sí, pero no en el Ateneo (46). Tenía razón el insigne político, las tinieblas, por

(42) Estas palabras de Moret tuvieron un amplio eco en la prensa habanera de la época. Véase, por ejemplo, los artículos del Diario de la Marina, titulad'os "Un voto de calidad", 23-2-1895, edición de la tarde y "Dos puntos fundamentales", 24-2-1895.

(43) Véase "Las reformas cubanas en el Ateneo", La Época, Madrid, 11-1-1895.

(44) "Crónica Política», El Nuevo Mundo, Madrid, 28-2-1895.

(45) Idem.

(46) «El problema antillano en el Ateneo. Conferencia del Sr. Moret»; El Liberal, Madrid, 22-2-1895. 
aquellas fechas, estaban más lejos, en Baire, en la manigua, donde el pueblo cubano comenzaba su definitiva guerra de independencia y adonde, según un cronista de la época, no llegaban los aplausos con los que el Ateneo recibía unas reformas demasiado tardías (47).

Spain's colonial problem on the eve of the Cuban War of Independence was a deeply debated subject at the time in the Athenaeum of Madrid, like in Parliament. The author's argument is that, rather than sponsoring a scientific debate on the matter, the Athenaeum wanted to influence Spain's public opinion and political élite of its own ideas on colonial reform.

(47) Véase Gallego, [3], pág. 258. 